\title{
Development and simulation of a hydrogen storage unit using metal hydrides
}

\author{
Maxime Botzung ${ }^{1, a}$, Serge Chaudourne ${ }^{1}$, Christian Perret ${ }^{1}$, Michel Latroche $^{2}$, \\ Annick Percheron-Guegan ${ }^{2}$ And Marty Philippe ${ }^{3}$ \\ 1 CEA Grenoble, DRT/LITEN/ DTH, 17 rue des Martyrs, 38054 Grenoble, France \\ 2 CNRS, CMTR-ICMPE-UMR7182, 2-8 rue Henri Dunant, 94320 Thiais Cedex, France \\ ${ }^{3}$ CEA, Équipe LEGI-GRETh, 17 rue des Martyrs, 38054 Grenoble Cedex, France
}

Received 15 March 2007, accepted 7 June 2007

\begin{abstract}
This paper presents a hydrogen storage system using metal hydrides for a Combined Heat and Power CHP) system. Hydride storage technology has been chosen due to project specifications: high volumetric capacity, low pressures $(<3.5 \mathrm{bar})$ and low temperatures $\left(<75{ }^{\circ} \mathrm{C}\right.$ : fuel cell temperature). During absorption, heat from hydride generation is dissipated by fluid circulation. An integrated plate-fin type heat exchanger has been designed to obtain good compacity and to reach high absorption/desorption rates. At first, the storage system has been tested in accordance with project specifications (absorption/desorption 3.5/1.5 bar). Then, the hydrogen charge/discharge times have been decreased to reach system limits. System design has been used to simulate thermal and mass comportment of the storage tank. The model is based on the software Fluent. We take in consideration heat and mass transfers in the porous media and a convective flow for cooling/heating the system during absorptions/desorptions. The hydride thermal and mass comportment has been integrated in the software. The heat and mass transfers experimentally obtained have been compared to results calculated by the model.
\end{abstract}

Key words: Hydrogen / storage / hydride

Résumé - Développement et modélisation d'un réservoir de stockage d'hydrogène sur hydrures métalliques. Dans cet article est présenté un stockage d'hydrogène sur hydrures métalliques intégré à un système de cogénération. Le choix du stockage d'hydrogène s'est orienté vers les hydrures afin d'obtenir une bonne capacité volumique avec des pressions faibles $(<3,5$ bar $)$ et des températures adaptées aux piles à combustibles $\left(<75^{\circ} \mathrm{C}\right)$. Pendant l'absorption, l'hydrure métallique dégage de la chaleur qui est dissipée par une circulation de fluide. Un échangeur à plaques et ailettes permet d'obtenir une bonne compacité avec des temps de chargements/déchargements rapides. Le système a été testé à débit constant puis à pressions constantes (absorption/désorption 3,5/1,5 bars). Les géométries ont été utilisées afin de simuler les transferts thermiques et massiques. On prend donc en compte un écoulement convectif couplé à une disparition massique et un apport de chaleur dans un milieu poreux. Cette simulation est basée sur le logiciel Fluent auquel est couplé le comportement de l'hydrure métallique. Les valeurs expérimentales obtenues ont ensuite été comparées aux valeurs résultant du modèle.

Mots clés : Hydrogène / stockage / hydrures

\section{Introduction}

Hydrogen storage represents a technological challenge to be solved for a commercial development of energy converters using hydrogen. Among the different hydrogen storage means (compressed gas, liquid hydrogen, adsorption and absorption in solids) reversible metal hydrides

\footnotetext{
${ }^{a}$ Corresponding author: maxime.botzung@cea.fr
}

are considered as a safe and volume efficient hydrogen storage medium, offering low pressure and high energy density. In the present work, a metal hydride buffer tank will be used in connection with a hydrogen production unit to supply a $40 \mathrm{~kW}$ stationary proton exchange membrane fuel cell. The production unit will provide hydrogen gas at a pressure of 3.5 bar while the fuel cell is supplied with gas at 1.5 bar. In between, the storage tank will 


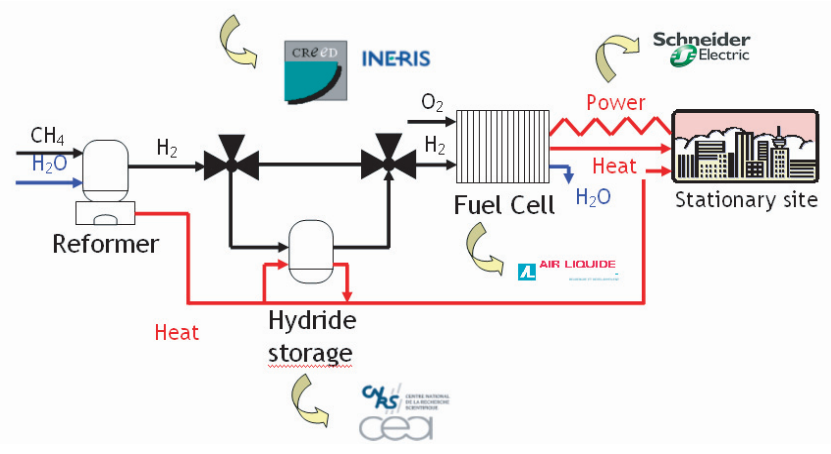

Fig. 1. The CHP system.

be used as a buffer working at an average temperature of $75{ }^{\circ} \mathrm{C}$. For this study, $\mathrm{LaNi}_{5}$ substituted derivatives ( $\mathrm{AB}_{5}$-type compounds) were chosen as hydrogen storage materials to reach the needs of the specific application.

The aim of this study is to test a Metal Hydride tank based on plate fin technology. The results of theses tests will validate a tool able to simulate the behaviour of the Metal Hydride tank.

\section{Presentation}

Figure 1 presents a Combined Heat and Power system CHP providing $40 \mathrm{~kW}$ electric power. The system includes: a hydrogen production unit using methane reforming, a proton exchange membrane fuel cell (PEMFC) and a hydrogen storage unit using metal hydrides.

The hydrogen consumption varies according to the energy demand of the user. Therefore a hydrogen buffer tank is needed to store the hydrogen excess produced during low consumption periods and to deliver it during high consumptions periods.

Specifications of the project impose some requirements for the storage device: reversible storage capacity, temperature and pressure of operation, kinetics, reaction in cycling and material cost. The methane reformer delivers a pressure of 3.5 bar while the fuel cell operates at 1.5 bar. Consequently, the absorption/desorption pressures of the hydride contained in the tank must be between those limits at $75{ }^{\circ} \mathrm{C}$ (working temperature of the fuel cell).

The design of the CHP system requires $5 \mathrm{~kg}$ hydrogen storage but in a first step, only a $0.1 \mathrm{~kg}$ prototype has been built and tested. According to the weight capacity of the alloy, the tank should contain $10 \mathrm{~kg}$ of hydride.

The Metal Hydride tank must fulfill the following conditions:

- Storage of $1.12 \mathrm{Nm}^{3} \mathrm{H}_{2}(100 \mathrm{~g})$ in $10 \mathrm{~kg}$ of Metal Hydride.

- Absorption in $15 \mathrm{~h}$ with 3.5 bars (Flow rate $\mathrm{H}_{2}$ : 75 NL.h ${ }^{-1}$ ) at $75^{\circ} \mathrm{C}$.

- Desorption in $9 \mathrm{~h}$ with 1.5 bars (Flow rate $\mathrm{H}_{2}$ : $125 \mathrm{NL} . \mathrm{h}^{-1}$ ) at $75^{\circ} \mathrm{C}$.
The study of $\mathrm{AB}_{5}$ [1] compounds led to the development of a composition adapted to the project needs. The hydride composition is $\mathrm{La}_{0.90} \mathrm{Ce}_{0.05} \mathrm{Nd}_{0.04} \mathrm{Pr}_{0.01} \mathrm{Ni}_{4.63} \mathrm{Sn}_{0.32}$. The absorption and desorption pressures of the hydride at $75{ }^{\circ} \mathrm{C}$ (2 and 1.85 bar respectively) are the most adapted to the specifications. The reversible storage capacity $(0.95 \%$ wt) has been optimized to our work conditions and chemical kinetics is fast.

Once the Metal Hydride has been chosen, a system able to contain the metal powder has been designed in order to obtain good thermal and mechanical properties.

\section{Design of the Metal Hydride tank ( $\mathrm{MH}$ tank)}

To decrease the hydrogen charging/discharging time, the heat exchange capability has to be improved. A rectangular design has been chosen to obtain a good compacity with an integrated plate fin type heat exchanger which is an efficient heat exchanger.

The various components of the plate fin type $\mathrm{MH}$ tank are shown in Figure 2. The metallic powder is filled into the metal hydride vessel with aluminium fins and aluminium Foam to improve the heat transfer. The heat exchanger and the MH vessel have been made with aluminium according to its high thermal conductivity.

The coolant flows from inlet of oil to outlet of oil through 12 square pipes in the heat exchanger.

A stainless steel filter has been introduced in the $\mathrm{MH}$ tank. This filter avoids MH transfer into hydrogen pipes (inlet/outlet of hydrogen) and prevents the powder from moving inside the tank. The MH tank can be moved and can be subjected to vibrations (inside a car). In addition, the pressure drop of hydrogen within the $\mathrm{MH}$ powder layer is reduced because the MH layer is small (35 millimetres).

The stainless steel cover integrates 6 groups of 3 thermocouples to measure the temperature at various levels inside the Metal Hydride bed ( $\mathrm{MH}$ bed). The indications given by the thermocouples have been used to understand and to model the heat transfer in the storage system.

The heat transfer characteristics in the Metal Hydride are measured by using thermocouples.

Several thermocouples (TC) have been introduced in the Metal Hydride vessel at different heights (Fig. 3).

Another effect to be taken into account is the powder volume expansion during hydrogen absorption. In fact, when hydrogen reacts with the alloy, it occupies cristallographic sites within the cell leading to an expansion of of the metallic matrix.

Accordingly, the metallic powder can expand $12 \%$ of its initial volume. If the expansion effect is not taken into account, it may generate stress which can cause damages on the MH tank. In order to limit the stress in the tank, a void space has been designed. This void space represents $20 \%$ of the total metal powder volume. In addition, to limit the stress generated by expansion during hydrogenation, the powder bed has been separated by dividers. 

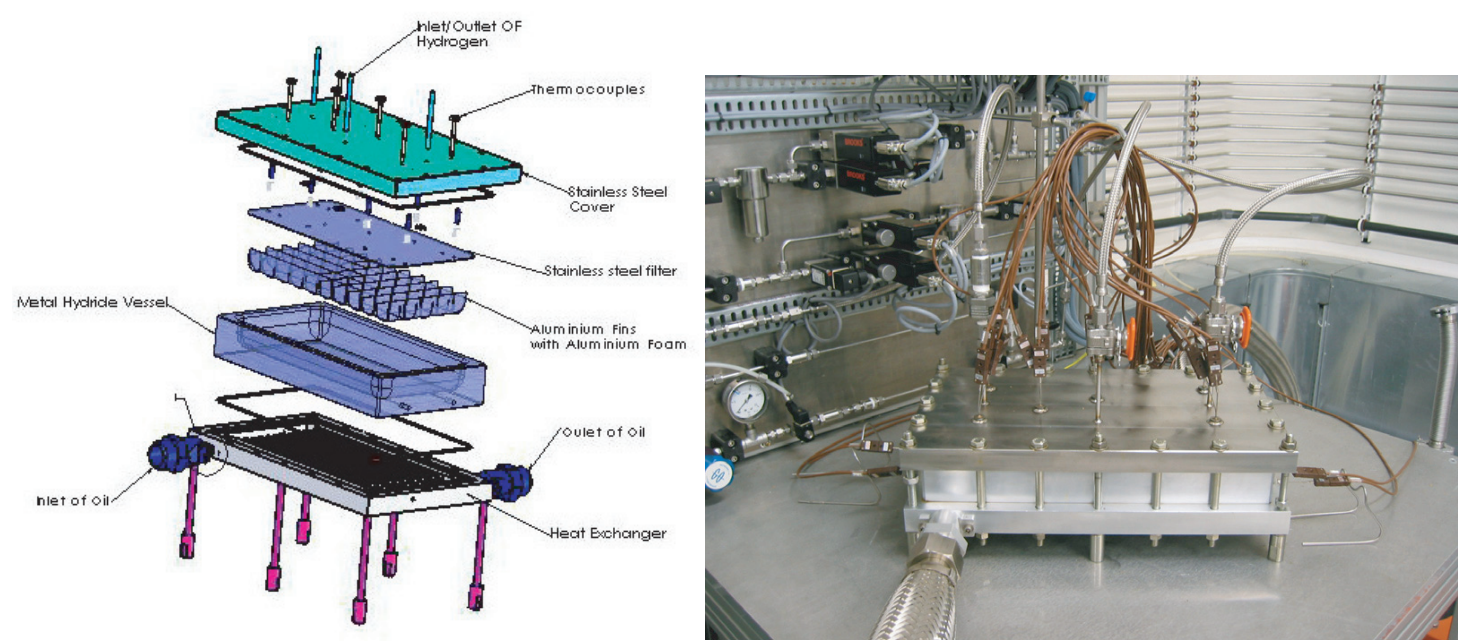

Fig. 2. Exploded view (left) of the Metal Hydride tank (right).

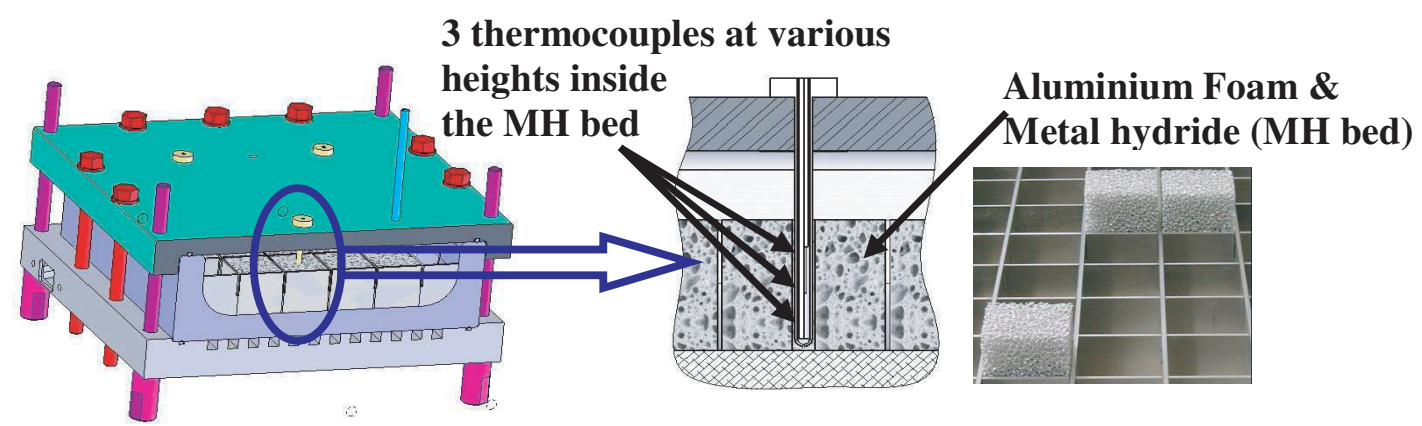

Fig. 3. Repartition of the three thermocouples at different levels inside the MH bed.

The dividers behave like aluminium fins and improve the heat transfer.

The filling of the $\mathrm{MH}$ vessel with the Metal Hydride powder has been done inside, a glove box under argon in order to avoid contamination of the powder by oxides or water.

This system has been designed to identify the thermal behaviour of the Metal Hydride storages systems. The aim is to use the heat from the fuel cell to desorb hydrogen and the test bench can simulate the fuel cell behaviour.

\section{Results}

\subsection{Constant flow rate}

Thereafter, absorption/desorption characteristics of the metal hydride tank will be given and the heat and mass transfers in the storage vessel will be presented.

In Figure 4, the absorption curve for a full charge is shown. The $\mathrm{H}_{2}$ flow rate is fixed at 125 NL.h ${ }^{-1}$. During absorption, the pressure increases from the equilibrium pressure $\left(0.7\right.$ bar at $\left.65^{\circ} \mathrm{C}\right)$ up to the set point pressure (3.5 bar). The Total $\mathrm{H}_{2}$ uptake is linear during $15 \mathrm{~h} 30$.

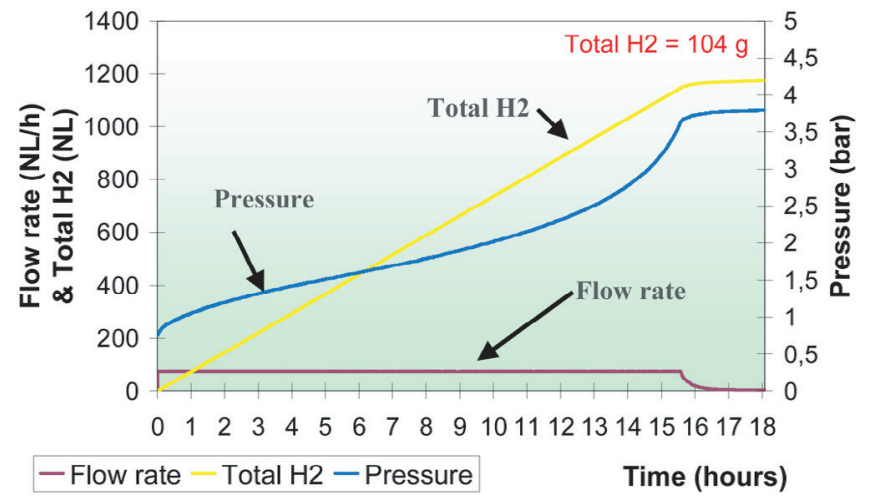

Fig. 4. Absorption cycle with a flow of 125 NL.h ${ }^{-1} \mathrm{H}_{2}$ (brown curve), a fluid circulation at $65{ }^{\circ} \mathrm{C}$ and a total $\mathrm{H}_{2}$ uptake of $104 \mathrm{~g}$ (yellow curve).

The $\mathrm{MH}$ tank results with constant flow rate are:

- Storage of $1.12 \mathrm{Nm}^{3} \mathrm{H}_{2}(100 \mathrm{~g})$ in $10 \mathrm{~kg}$ of Metal Hydride.

- Absorption of $1.15 \mathrm{Nm}^{3} \mathrm{H}_{2}$ (104 g) in $15 \mathrm{~h} 30$ (Flow rate: $75 \mathrm{NL} . \mathrm{h}^{-1}$ ) at $65{ }^{\circ} \mathrm{C}$.

- Desorption of $1.33 \mathrm{Nm}^{3} \mathrm{H}_{2}$ (119 g) in $10 \mathrm{~h} 48$ (Flow rate: $125 \mathrm{NL} \cdot \mathrm{h}^{-1}$ ) at $85{ }^{\circ} \mathrm{C}$. 

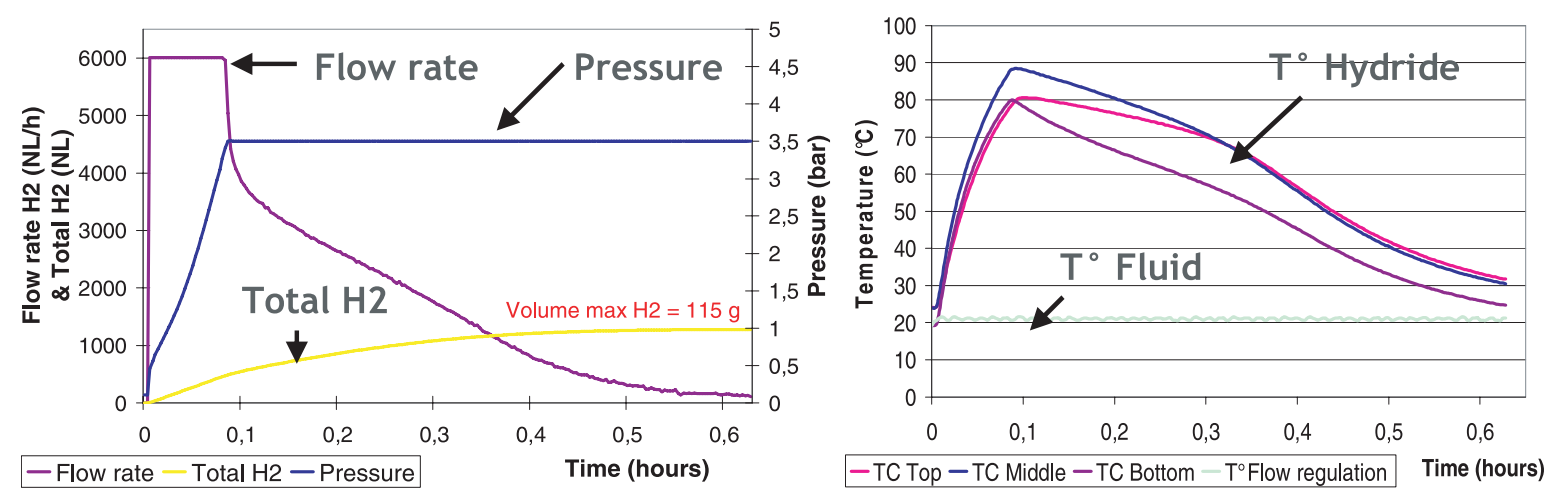

Fig. 5. Absorption cycle in constant pressure mode (left) and thermal responses inside the MH bed (right). The Mass Flow meters are limited to 6000 NL.h ${ }^{-1}$.

\subsection{Constant pressure}

The total absorption/desorption rates are faster if the absorption/desorption pressures are constant and the flow rate varies. Figure 5 shows the charging characteristics of the plate fin type MH-tank. The hydrogen supply pressure is fixed at 3.5 bar. The cooling fluid rate is set at $10 \mathrm{~m}^{3} \cdot \mathrm{h}^{-1}$ at $20^{\circ} \mathrm{C}$.

In the constant pressure mode, the amount of hydrogen charged (Total $\mathrm{H}_{2}$ ) reaches $100 \mathrm{~g}$ of hydrogen in 20 min (90\% of the effective storage capacity).

The MH tank results with constants pressures are:

- Storage of $1.12 \mathrm{Nm}^{3} \mathrm{H}_{2}(100 \mathrm{~g})$ in $10 \mathrm{~kg}$.

- Absorption in 20 min (Pressure: 3.5 bar) at $20^{\circ} \mathrm{C}$.

- Desorption in $1 \mathrm{~h} 50$ (Pressure: $1.5 \mathrm{bar}$ ) at $75^{\circ} \mathrm{C}$.

The temperature of the fluid coolant and the different temperatures of the thermocouples in the MH bed during absorption are given in Figure 5. Theses temperatures are measured from the centre of the system (blue ring in Fig. 3). During the first step of absorption, a strong increase of temperatures in observed in the $\mathrm{MH}$ bed. Once the set point pressure has been reached (3.5 bar), the temperature starts to decrease down to cooling fluid temperature.

\section{Simulation}

\subsection{The model}

To simulate the absorption/desorption cycle, a compressible flow $\left(\mathrm{H}_{2}\right)$ has been taken in account with the continuity equation associated with a mass source term which is negative during absorption and positive during desorption. The momentum conservation equations have been used for a porous-media modelled by the addition of a momentum source term to the standard fluid flow equations. This source term is composed of two parts: a viscous loss term (Darcy) and an inertial loss term. Energy equation is used with an energy source term which is exothermic during absorption and endothermic during desorption. The effective thermal conductivity in the

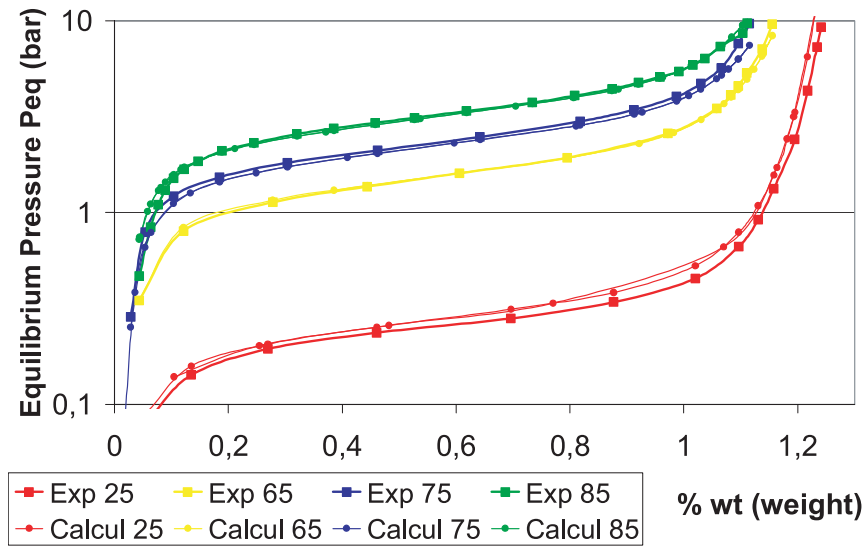

Fig. 6. PCI curves of the hydride $\mathrm{MmNi}_{5-x} \mathrm{Sn}_{x}$ at $25,65,75$ and $85^{\circ} \mathrm{C}$.

porous medium is computed by FLUENT as the volume average of the fluid conductivity and the solid conductivity (porosity 0.5 ).

At the end, to regulate the temperature during absorption/desorption, a cooling/heating fluid in the square pipes is modelled as a laminar or a turbulent convective flow.

\subsection{The hydride behaviour}

In order to simulate the thermal and mass behaviours of the tank, the thermal and mass behaviour of the hydride have to be integrated in the Fluent software.

Under isothermal conditions, metal hydrides exhibit the pressure-composition behaviour of a phase change. Figure 6 provides an illustration of this relationship for a decomposition of a metal hydride. Composition (\% wt weight) is plotted on the $x$-axis and pressure is plotted on a logarithmic scale on the $y$-axis. At a given temperature $\left(25,65,75\right.$, or $85^{\circ} \mathrm{C}$ plotted), the metal hydride $\left(\mathrm{MmNi}_{5-x} \mathrm{Sn}_{x}\right.$ type) will absorb or release hydrogen along a equilibrium pressure $\left(P_{\text {eq }}\right)$, with a sharp decrease in pressure at low compositions and a sharp increase at high compositions. Named as a pressure-composition-isotherm 

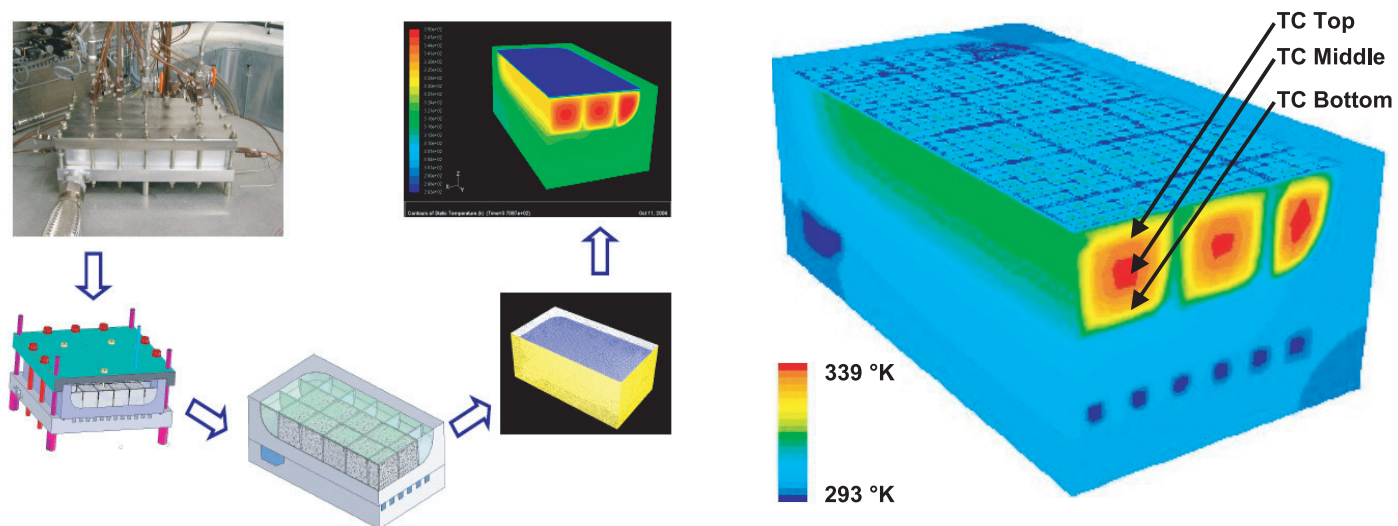

Fig. 7. The facility and its modelling, and contours of temperatures during absorption at time $=110 \mathrm{~s}$, hydrogen absorbed $=$ $16 \mathrm{~g}$.
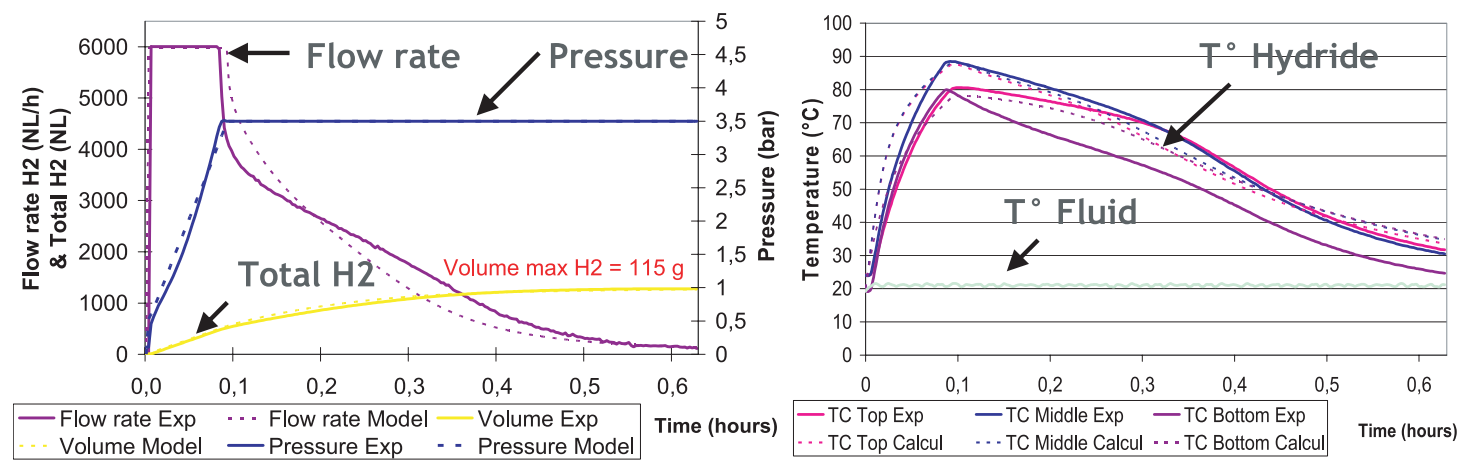

Fig. 8. Experimental results VS numerical results. The experimental results are plotted in continuous lines and the simulation results are plotted in discontinuous lines.

(PCI), this plot is commonly used to illustrate the thermodynamic behaviour of a metal hydride.

The numeric correlation (PONS model) showed below has been used to simulate the PCI curves. Figure 6 shows the very little difference between the experimentations at $25,65,75$ and $85{ }^{\circ} \mathrm{C}$ and results of the numeric correlation [2]. $(H / M)^{\prime}=H / M-h / m$

$$
\begin{aligned}
\ln P_{\mathrm{eq}}=A-\frac{B}{T_{\mathrm{h}}}+C \cdot(H / M)^{\prime}+D \cdot\left[\tan \left(\frac{\pi}{2} \frac{(H / M)^{\prime}}{(H / M)_{\max }^{\prime}}\right)\right]^{n} \\
+E \cdot\left[\tan \left(\frac{\pi}{2} \frac{(H / M)^{\prime}}{(H / M)_{\max }^{\prime}}\right)\right]^{-m}
\end{aligned}
$$

where $A, B, C, D, E, n, m, h / m,(H / M)_{\max }^{\prime}$ are constants $P_{\text {eq }}$ the equilibrium pressure. $T_{\mathrm{h}}$ is the hydride temperature and $H / M$ is the hydrogen on metal ratio (\%weight in Fig. 6).

In order to charge a metal hydride, hydrogen pressure must be supplied above the equilibrium pressure $\left(P_{\text {eq }}\right)$ at a given temperature. Likewise, hydrogen gas liberated from a metal can only be supplied at or below the equilibrium pressure. Additionally, the rate of reaction is commensurate with temperature and the difference between hydrogen pressure and equilibrium pressure. Therefore, charging and discharging kinetics is dependant on both the temperature and the hydrogen pressure.
A numeric correlation has been used to simulate thermal and mass kinetics during [3]:

Absorption: $\frac{\mathrm{d} n}{\mathrm{~d} t}=C_{\mathrm{a}} \exp \left(\frac{-E_{\mathrm{a}}}{R \cdot T_{\mathrm{h}}}\right) \ln \left(\frac{P_{\mathrm{H}_{2}}}{P_{\mathrm{eq}}}\right)$

Desorption: $\frac{\mathrm{d} n}{\mathrm{~d} t}=C_{\mathrm{d}} \exp \left(\frac{-E_{\mathrm{d}}}{R \cdot T_{\mathrm{h}}}\right) \ln \left(\frac{P_{H_{2}}}{P_{\mathrm{eq}}}\right)$

where $C_{\mathrm{a}}, E_{\mathrm{a}}$ are absorption constants and $C_{\mathrm{d}}, E_{\mathrm{d}}$ are desorption constants. $T_{\mathrm{h}}$ is the hydride temperature, $P_{\mathrm{H} 2}$ is the hydrogen pressure and $P_{\mathrm{eq}}$ is the equilibrium pressure.

\subsection{Meshing}

The design of the tank has been integrated in the Fluent software from Solidworks and the metal hydride behaviour has been integrated in the numerical tool (Fig. 7).

\section{Simulation results}

The simulation results are shown in Figure 8. The experimental and simulation results are quite similar so the simulation tool have been validated. 


\section{Conclusions}

A precedent study [1] leads to the development of the composition $\mathrm{MmNi}_{5-x} \mathrm{Sn}_{x}$ for which the reversible storage capacity was optimized $(0.95 \mathrm{wt} \%)$ in a narrow pressure range (absorption 3.5 bar, desorption 1.5 bar) at $75{ }^{\circ} \mathrm{C}$.

This Metal Hydride has been charged in a plate-fin type metal hydride tank with an effective storage capacity of $1.2 \mathrm{Nm}^{3}(106 \mathrm{~g})$ of hydrogen.

The important characteristics of the Metal Hydride tank have been analyzed and the obtained performances fulfilled the objectives imposed by a stationary cogeneration system.

A numerical tool has been created to simulate the thermal and mass comportment of the hydrogen tank. The simulation is operational and has been validated by the experiments done with the storage system. This numerical tool will be used to design future Metal Hydride storage systems.

\section{References}

[1] V. Iosub, M. Latroche, J.-M. Joubert, A. PercheronGuégan, Optimisation of $\mathrm{MmNi}_{5-x} \mathrm{Sn}_{x}(\mathrm{Mm}=\mathrm{La}, \mathrm{Ce}, \mathrm{Nd}$ and $\operatorname{Pr}, 0.27<x<0.5)$ compositions as hydrogen storage materials, Int J. Hydrogen Energy 31 (2006) 101-108

[2] M. Pons, Heat transfers in the LaNi5 powder coupled with hydrogenation reaction, Ph.D., 1991

[3] S.B. Nasrallah, A. Jemni, Study of a two-dimensional heat and mass transfer during absorption/desorption in a metal-hydrogen reactor, Int J. Hydrogen Energy 20 (1995) $43-52$

To access this journal online: www.edpsciences.org/meca 